\title{
OS CONSELHOS COMUNITÁRIOS DE SEGURANÇA PÚBLICA: DINÂMICAS E AVANÇOS de UMA POLÍTICA PÚBLICA NO RIO DE JANEIRO ${ }^{1}$ THE COMMUNITY ADVICE FOR PUBLIC SAFETY: DYNAMICS AND ADVANCES OF A PUBLIC POLICY IN RIO DE JANEIRO
}

\author{
João Trajano Sento-Sé ${ }^{1}$, Marcele Frossard Antonio ${ }^{1}$, Conrado Werneck ${ }^{1}$, Raphaela Boaes ${ }^{1}$ \\ ${ }^{1}$ Universidade do Estado do Rio de Janeiro (UERJ), Rio de Janeiro, RJ, Brasil
}

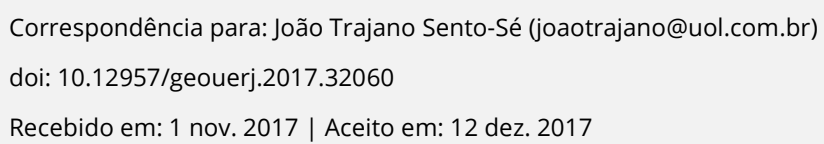

\section{RESUMO}

O artigo apresenta os resultados de uma pesquisa sobre as principais questões e atores envolvidos nos debates travados nos conselhos comunitários de segurança pública do estado do Rio de Janeiro. Utilizando como fonte as atas das reuniões ocorridas entre os anos de 2005 e 2012, a análise está focada na compreensão das dinâmicas que presidem o funcionamento desses conselhos, entendidos como instrumentos importantes para a adoção de estratégias territorializadas para o campo da segurança e para a aproximação entre agentes locais e autoridades policiais

Palavras-chave: Associativismo, segurança pública, sociedade civil, violência

\section{ABSTRACT}

This paper present a series of research findings about the main concerns and agents engaged in the debate in public security community councils in Rio de Janeiro state. Using as a source the minutes of the meetings that have taken place between 2005 and 2012, the analysis is focused in comprehending the dynamics that hold those councils functioning, known as important tools in the adoption of a territorial approach in the public security filed and in the convergence between local agents and police authorities.

Keywords: Associativism, public security, civil society, violence

\section{INTRODUÇÃO}

Os conselhos comunitários de segurança pública foram criados no Rio de Janeiro no ano de 1999 , no bojo de uma série de outras iniciativas veiculadas pelo governo do estado como estratégias de mudança radical da segurança no estado ${ }^{2}$. Desde seus passos iniciais, ficou estabelecido que caberia à Secretaria de Segurança Pública a responsabilidade de estimular a fundação dos conselhos e acompanhar seu funcionamento, cuidando para que eles cumprissem os objetivos previstos no ato de sua criação. Após alguns anos de relativa indigência e de sobrevida garantida apenas por esforços intermitentes e

\footnotetext{
${ }^{1}$ Esse artigo é decorrente de pesquisa realizada graças ao apoio do Programa Pró-ciência da UERJ, ao qual João Trajano Sento-Sé é vinculado e ao Programa Prioridade Rio da FAPERJ. Marcio Lázaro, Thiago Ferreira Anastácia Santos também participaram da pesquisa. Agradecemos a Fernanda Novaes Cruz pelo apoio no tratamento dos dados.

${ }^{2}$ Para uma breve apresentação do conjunto de iniciativas e da retórica oficial para elas ver SENTO-SÉ et ali. 2012.
} 
localizados, a proposta passou por uma grande reestruturação em 2005. A proposta dos conselhos após estas mudanças foi abrigada no Instituto de Segurança Pública (ISP) e recebeu maior atenção dos gestores de segurança pública do estado, ocupados em potencializar seus recursos para o cumprimento das metas a eles atribuídas.

O objetivo desse artigo é analisar alguns aspectos do funcionamento desses conselhos. Mais especificamente, pretendemos observar o ritmo e a intensidade de seus encontros, estimar em que regiões do estado e de sua capital tais encontros são mais regulares, que atores são mais repetidamente citados e quais as questões em que se concentram os debates travados. A fonte utilizada é o conjunto de atas enviadas pelos conselhos ao Instituto de Segurança Pública (doravante ISP). Como fonte eventual de apoio, faremos alusões pontuais a depoimentos recolhidos durante o trabalho de campo realizado em alguns conselhos especificamente, não sendo essa, contudo, a referência principal do estudo.

A fonte aqui utilizada impõe uma série de limitações e reservas que serão esclarecidas na próxima seção. Sua utilização justifica-se por ser o único recurso disponível para uma discussão em escala e diacrônica das dinâmicas e particularidades dos conselhos comunitários e de seu lugar nos debates sobre o tema da segurança no Rio de Janeiro.

\section{As atas dos conselhos de segurança como documentos e fontes de orientação}

A redação e o envio das atas de reuniões dos conselhos de seguranças à sua coordenadoria, vinculada à secretaria de segurança pública, foi uma determinação estipulada pelo governo estadual já nos momentos iniciais de funcionamento desses fóruns. Há nessa determinação uma indisfarçável ambivalência. Por um lado, o registro das atas permitiria aos gestores e planejadores da secretaria de segurança dispor de um recurso a mais de informação para orientar suas escolhas e estratégias, tomando o recorte territorial como referência. Supondo que nas reuniões os debates se dariam em torno dos principais problemas e demandas da área coberta pelos conselhos, e imaginando que tais debates seriam registrados em atas, os gestores disporiam das expectativas da população 
documentadas e explicitadas em situações de contato direto com as autoridades policiais locais. Teríamos, então, um mundo em que o canal de acesso do poder público à sociedade e vice versa seria quase ótimo. Por outro lado, o imperativo de redação e envio das atas funcionaria como recurso indutivo, ou mesmo coercitivo, pelo ISP, para que as autoridades policiais não somente participassem, mas estimulassem a realização de encontros com os atores das suas respectivas áreas de atuação. A resposta a essa estratégia do ISP resultou que, em determinadas situações, os comandos dos batalhões assumissem um verdadeiro protagonismo na organização e rotinização dos encontros de alguns conselhos.

Os esforços no sentido da produção e envio de atas não se limitaram às reuniões ordinárias dos conselhos comunitários, previstas para ocorrerem mensalmente. Na mesma época em que foram encampadas as primeiras iniciativas para a criação dos conselhos, foram instituídos os chamados cafés da manhã comunitários nos batalhões da Policia Militar. A ambição desta inciativa era intensificar esforços de aproximação de moradores e demais atores radicados nas áreas (comerciantes, profissionais de ensino e saúde, prestadores de serviço, etc.) sob cobertura de cada batalhão às autoridades policiais. Pudemos perceber que em muitas regiões, o registro desses encontros, imaginados como meramente informais e sociais, também passou a ser feito e encaminhado ao ISP em formato de atas.

Previsto desde o início do funcionamento dos conselhos, em 1999, o encaminhamento das atas somente passou a ser estimulado com maior contundência pelo ISP a partir de 2005, no conjunto de iniciativas voltadas para reestruturá-los e fortalecê-los. Ainda assim, não há qualquer indicio de que esse material tenha sido utilizado ao longo do tempo. Ele foi, durante anos, armazenado em caixas em uma sala do instituto à espera de algum uso. O formato das atas foi livre durante muito tempo. Cada responsável por sua produção deu-lhe a configuração que lhe pareceu melhor, mas é possível imaginar que, por vias informais, consagrou-se um padrão predominante. Os documentos começam com a lista dos presentes, destacando-se a presença de autoridades ou representantes de instituições públicas ou privadas prestadoras de serviços, e breves notas com a menção dos conteúdos das reuniões. Há, em geral, a título de cabeçalho, a data, o local do encontro e o registro da AISP a que o conselho está 
vinculado. Pelo que pudemos apurar no trabalho de campo, a redação e o envio da ata fica a cargo, na maior parte das vezes, do presidente do conselho, embora não sejam raros os casos em que tal incumbência seja assumida pelo comandante do batalhão responsável pela área. Esse é o caso, sobretudo, de conselhos em início de funcionamento ou com participação muito limitada.

O respeito à determinação de envio de atas é tão irregular quanto os procedimentos adotados para fazê-lo. Como indicaremos a seguir, o fluxo de atas é bastante inconstante, bem como a qualidade de seus dados. Encontramos atas longas e com informações detalhadas com quase tanta frequência com que lidamos com atas redigidas à mão e compostas por informações telegráficas, por vezes quase ilegíveis. A partir de 2013, o ISP instituiu um modelo de ata eletrônica, num passo adiante no esforço de aprimoramento do registro, padronização dos procedimentos e viabilização da consulta, consolidação e análise de seus conteúdos. A adesão a esse modelo, contudo, ainda é baixa e consome, hoje, uma parte dos esforços dos profissionais do ISP nas relações com os diferentes conselhos.

O material por nós utilizado, portanto, é de caráter artesanal e fornece indícios a serem explorados de modo cauteloso. Cada ata foi copiada eletronicamente e armazenada em um banco de dados. As atas originalmente manuscritas foram digitadas pela equipe de pesquisadores e incluídas na base de dados.

Uma vez armazenados, os documento foram processados através da utilização do programa NVivo, ferramenta com quê procuramos, a partir da utilização de categorias inspiradas em grande parte pelo que viemos inventariando durante outras etapas da pesquisa, traçar um grande cenário sobre as dinâmicas dos conselhos comunitários de segurança.

A metodologia de análise utilizada no NVivo não foi semântica, ou seja, as palavras não foram contadas a partir de seu significado, mas sim por sua recorrência. As buscas foram automáticas, selecionamos palavras e conjuntos de palavras e realizamos a varredura. A principal crítica a este modelo é o de considerar as palavras deslocadas de seu contexto. Porém, o número de atas é muito alto, o que dificultava uma análise detalhada. O propósito era mapear os possíveis temas recorrentes discutidos nas reuniões de conselho e a busca automática permite visualizar justamente isso. As 
palavras que poderiam ter duplo sentido, como participação, que indica ao mesmo tempo participação social e participação em uma reunião, não foram contabilizadas no resultado final.

Desta forma, reconhecemos os limites deste tipo de busca, mas compreendemos que ela seria fundamental para o tipo de aproximação que pretendíamos em relação às atas e aos temas que elas descrevem. Assim como as fontes utilizadas, o trabalho de análise é artesanal, descritivo e exploratório. Não tivemos a pretensão de fazer análise dos discursos o que, por sinal, não seria possível mesmo utilizando outros métodos de exploração do material utilizado. Como o banco de dados é muito extenso, considerou-se a possibilidade de erros, como repetição de atas, a inferência realizada por três pesquisadores concluiu que este erro é inferior à $5 \%$ do total, e que portanto os dados e os documentos são válidos.

Como recorte cronológico, estipulamos para a discussão o período compreendido entre os anos de 2005, quando as atividades dos conselhos ganham um impulso expressivo, e 2012, ano imediatamente anterior ao início dos esforços pela adesão ao modelo de atas eletrônicas. Entendemos que assim, cobrimos o período e o material mais ingrato para o analista que pretenda conferir rendimento à única documentação disponível para a memória dos conselhos comunitário de segurança. Como o gráfico a seguir atesta, o fluxo de atas encaminhadas aos ISP apresenta uma curiosa inconstância.

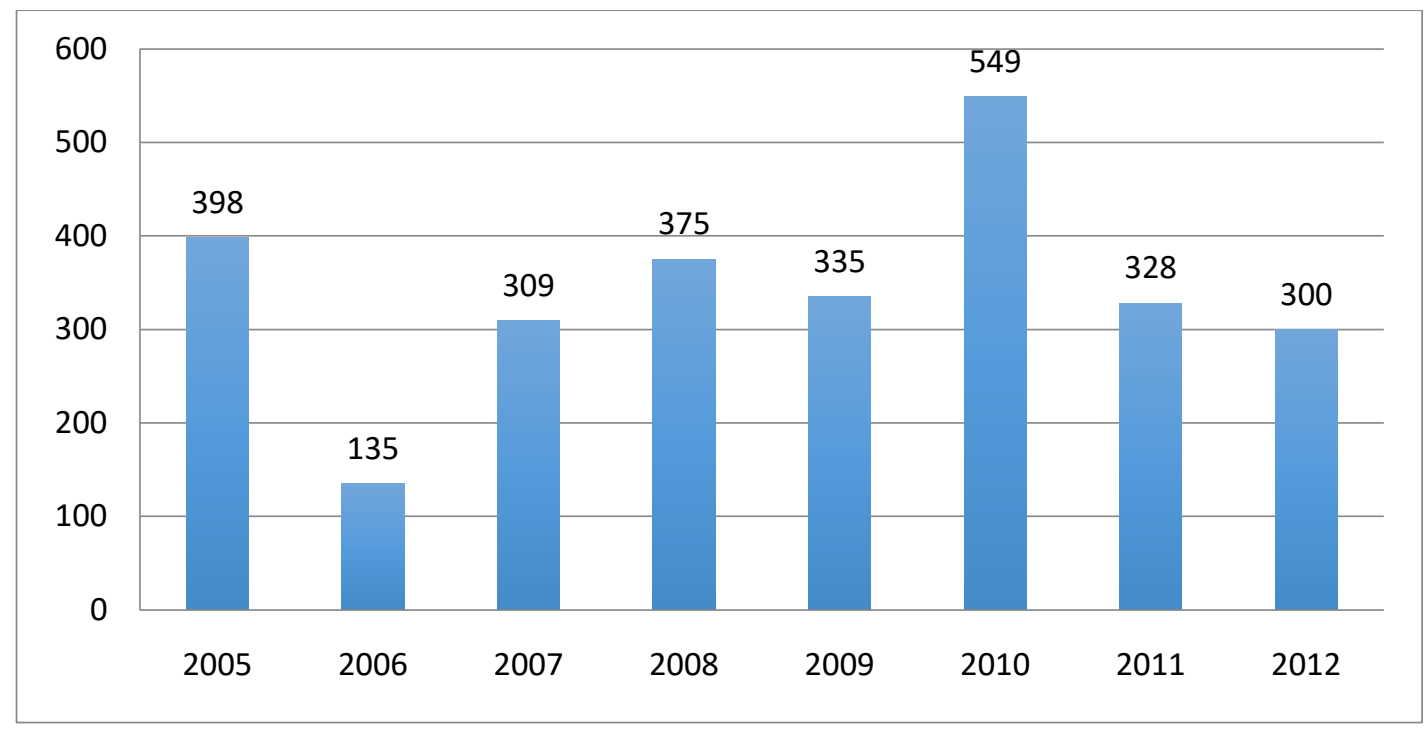

Gráfico 1. Total de Atas por Ano - 2005-2012. Fonte: Atas dos Conselhos Comunitários de Segurança 
Provavelmente em virtude dos esforços concentrados na revitalização dos conselhos, o ano de 2005 é aquele em que se registra a segunda maior incidência de encaminhamentos de atas, sendo superado apenas pelo "pródigo" ano de 2010. É interessante observar que esses dois anos de maior registro de atas são sucedidos por quedas significativas, o que parece sugerir a dificuldade dos envolvidos em manter alguma regularidade ou mesmo promover um crescimento e adesão permanentes ao processo imaginado como recurso de interlocução dos conselhos com as autoridades da Secretaria de Segurança Pública. Dos oito anos estudados, dois aparecem com um fluxo maior, estando o ano de 2005 muito próximo dos números que constituiriam a média do período. $\mathrm{O}$ ano imediatamente posterior à retomada do programa dos conselhos, porém, apresenta números bem abaixo da média o que sugere uma certa instabilidade do fluxo. A ideia de encaminhamento para o ISP embute a presunção de que o conteúdo de demandas e os diagnósticos produzidos nos conselhos fariam parte dos insumos do instituto para a orientação dos estrategistas da área de segurança formularem e orientarem suas ações. Aparentemente são grandes as dificuldades para a consolidação e adensamento desse fluxo.

A distribuição das atas pelos conselhos revelou uma surpresa para nós. Segundo o projeto original, ficou determinado que os conselhos seriam estruturados segundo as diferentes AISPs (Áreas Integradas de Segurança Pública), criadas na mesma onda em que se deu a criação dos conselhos. Originalmente, as AISPs foram definidas segundo as áreas de atuação dos batalhões da Polícia Militar. Desse modo, na capital, cada AISP equivale a vários bairros (por exemplo, a AISP 2 cobre os bairros de Botafogo, Urca, Glória, Catete, Laranjeiras e Cosme Velho). O que pode soar problemático para a capital, revelava-se muito mais delicado no que diz respeito ao interior, onde uma AISP pode corresponder a vários municípios. As ressalvas a essa escolha são óbvias: um alcance tão extenso para um mecanismo concebido tendo como recorte a atuação territorial se revelava uma contradição em termos. Ainda assim, o critério de organização dos conselhos por AISPs foi mantido até o momento de sua revitalização, quando o investimento em criação de conselhos por localidades foi estimulado, sobretudo no interior. A dúvida que pairava era em que medida tal estímulo teve resposta positiva.

O já mencionado caráter artesanal das atas não nos permitiu organiza-las por conselho. Nossa unidade de análise teve que ser as AISPs. Com isso, é problemático, dada a análise por nós realizada, precisar 
com quantas atas cada conselho de uma mesma AISP contribuiu para o total de atas registrada sob sua jurisdição. Esse problema ocorre, sobretudo, no interior, em que cada AISP cobre mais de um município o que levou, com o tempo, a que houvesse dois ou mais conselhos em uma única AISP. Ainda assim, o volume de atas distribuído pelas diferentes áreas do estado nos fornece pistas e revela algumas dinâmicas interessantes que merecem registro. Dividimos nosso material em quatro grandes áreas: capital, interior, Baixada Fluminense e Grande Niterói. O resultado, até certo ponto surpreendente, está exposto a seguir.

\begin{tabular}{lrrrrrrrrr}
\hline Região & $\mathbf{2 0 0 5}$ & $\mathbf{2 0 0 6}$ & $\mathbf{2 0 0 7}$ & $\mathbf{2 0 0 8}$ & $\mathbf{2 0 0 9}$ & $\mathbf{2 0 1 0}$ & $\mathbf{2 0 1 1}$ & $\mathbf{2 0 1 2}$ & Total \\
\hline Interior & 139 & 46 & 118 & 186 & 172 & 235 & 140 & 120 & 1156 \\
Capital & 178 & 67 & 113 & 106 & 56 & 179 & 99 & 95 & 893 \\
Baixada Fluminense & 59 & 17 & 71 & 52 & 61 & 86 & 35 & 44 & 425 \\
Grande Niterói & 22 & 5 & 7 & 31 & 46 & 49 & 54 & 41 & 255 \\
\hline Total & 398 & 135 & 309 & 375 & 335 & 549 & 328 & 300 & $\mathbf{2 7 2 9}$ \\
\hline
\end{tabular}

Tabela 1. Total de atas por Região - 2005 a 2012

Fonte: Atas dos Conselhos Comunitários de Segurança

Como pode ser visto, nos dois primeiros anos de nossa série o volume de atas da capital supera o de todas as demais áreas por nós definidas. Isso não nos surpreende, afinal, de 41 AISPs, 19 estão na capital, enquanto o interior reúne 13, a Baixada é coberta por 6, e Grande Niterói compreende apenas 3 AISPs. Não somente há um maior número de AISPs na capital, mas, por óbvio, ali está também a maior parte do efetivo policial. Acrescente-se a esses fatores a concentração de iniciativas e atenções das autoridades na área em que, ao menos em tese, concentra-se também o maior volume de problemas. Finalmente, dado o perfil demográfico, supõe-se que a capacidade de mobilização e organização da sociedade seja maior na capital. Temos, assim, bons argumentos para justificar a expectativa de concentração de maior número de atas no total de conselhos em funcionamento na capital. O que de certa forma surpreende é a mudança que se verifica a partir de 2007. Desde então, o maior número de atas recebidas pelo ISP vem do interior, sempre apresentando um total expressivamente maior, se comparado aos totais vindos da capital. No cômputo final, as atas do interior perfazem pouco menos da metade do material por nós analisado. 
Há bons indícios de que o critério inicial em que cada conselho correspondia a uma AISP foi superado no interior. Comandantes de Companhias são não somente autorizados, mas instados a participar de encontros locais e contribuir para que moradores, comerciantes e atores locais se reúnam em novos conselhos. Os chamados cafés da manhã nos batalhões, instituídos à mesma época da criação dos conselhos e também eles concebidos como formas de aproximação das polícias com as respectivas comunidades, não somente se perpetuaram ao longo do tempo como também foram, em alguns casos, registrados documentalmente. Nesse sentido, tudo indica que os esforços conjugados das autoridades vinculadas ao ISP junto a associações e grupos locais deram resultado e áreas enfeixadas nessa grande categoria, o interior, que agrega regiões tão distintas entre si como a área de Campos, a Região dos Lagos e a região serrana, têm mostrado uma boa capacidade de mobilização e articulação a partir da ideia dos conselhos de segurança pública. Temos, portanto, que, após um primeiro e breve momento de maior incidência de reuniões na capital, ocorreu uma espécie de interiorização dos conselhos comunitários de segurança no Rio de Janeiro ${ }^{3}$.

Essa tendência, por outro lado, não nos deve induzir a pensar que os conselhos estão igualmente articulados por todo o estado. Do total de 2729 atas, 918, ou seja, cerca de um terço, está concentrado em 7 AISPs, sendo todas elas localizadas no interior. Isso significa que 7 das 13 AISPs que cobrem o interior são responsáveis por cerca de 79\% das atas recolhidas dessa grande área do estado. Desse modo, somos instados a pensar que a articulação dos conselhos está associada a fatores locais que, por conseguinte, não se manifestam igualmente em cada área de cada uma das quatro regiões definidas para a análise. É de se destacar, por outro lado, a maior capacidade revelada pelo interior em fazer uso do fluxo de informação com o poder público através do Instituto de Segurança Pública. Seria temerário inferir daí que, no que concerne à segurança pública, teríamos um interior mais mobilizado, com canais de interlocução sociedade civil/Estado mais azeitados. É de se notar, no entanto, que, tendo em vista a maior distância entre tais regiões e o centro político e administrativo do Estado, a capacidade de certas áreas dessa grande e diversificada região do estado se revelou bastante surpreendente e positiva.

\footnotetext{
${ }^{3}$ Tomamos aqui de forma livre, apenas para fins expositivos, a presunção de que o número de atas guarda alguma relação com níveis de articulação e mobilização dos conselhos.
} 
Vejamos, então, do que falam conselheiros e participantes desses encontros, à luz daquilo que tem sido registrado em atas.

\section{Do quê tratam os conselhos de segurança pública}

Assim como ocorreu em outros campos das políticas públicas no Brasil, desde meados dos anos de 1980, o recurso à criação de conselhos foi encarado por muitos gestores da segurança pública como ferramenta adequada para o aperfeiçoamento da abordagem para o setor . Por sua criação pretendeuse dar um passo na direção da maior qualificação de políticas e democratização de seus processos. As duas últimas décadas do século XX foram terreno fértil no Brasil, para a criação de mecanismos dessa natureza (AVRITZER, 2008; GOHN, 2003; DAGNINO, 2002). Conselhos temáticos, gestores e comunitários com mandatos de consulta, fiscalização, discussão ou deliberação, mecanismos de participação como associações e fóruns, ou experiências como as que instituíram o orçamento participativo em muitos municípios brasileiros tiveram, invariavelmente, a ambição de ampliar o escopo democrático, sem prejuízo à qualidade das políticas. Muito pelo contrário, um dos pressupostos de base dessa vaga era que quão mais participativos os processos de debate, desenho e definição de políticas, mais efetivas elas seriam porque mais próximas estariam das expectativas de seus beneficiários.

A aposta nas formas participativas, portanto, está associada a uma expectativa normativa, aprofundar a experiência democrática pela via da ampliação dos atores nela engajados, e a uma expectativa pragmática, aperfeiçoar as políticas sociais através da abertura para que seus beneficiários participem dos processos de decisão. Segundo Avritzer, conselhos de políticas são “(...) desenhos institucionais de partilha do poder e são constituídos pelo próprio Estado, com representação mista de atores da sociedade civil e atores estatais." (AVRITZER, 2008, p. 44). Ainda segundo o autor, podemos definir ao menos três desenhos participativos observados no Brasil pós-redemocratização.

A primeira forma em que os cidadãos ou associações podem participar dos processos decisórios é a denominada experiência de baixo para cima, em que o ingresso de qualquer cidadão é liberado e as formas institucionais de participação são articuladas de baixo para cima, vale dizer, das bases sociais e 
locais para os níveis mais institucionalizados de discussão e decisão. Segundo Avritzer, as experiências de orçamento participativo seriam os casos mais conhecidos e estudados dessa primeira modalidade.

A segunda maneira de formação de instâncias participativas, ainda com Avritzer, se dá através de mecanismos de partilha do poder, onde agentes estatais e atores da sociedade civil compartilham simultaneamente os processos deliberativos. 0 fato de se tratarem de instâncias reguladas por leis que preveem sanções caso o processo participativo não ocorra e por incorporarem um número menor de atores diferencia essa segunda modalidade da primeira.

No terceiro modelo proposto por Avritzer, os atores da sociedade civil não participam propriamente dos processos decisórios, mas são chamados para referendá-lo publicamente, funcionando como uma espécie de instrumento de chancela. Os três tipos propostos por Avritzer correspondem aproximadamente a três experiências verificadas no Brasil nas últimas três décadas. Os conselhos de política estariam enquadrados no segundo tipo, o modelo de partilha do poder. Seu funcionamento, contudo, varia, segundo as próprias análises empíricas que se avolumam a partir do final dos anos 1990, em função de um conjunto de variáveis que vão da capacidade de articulação dos atores civis à disposição dos agentes do Estado em efetivamente compartilhar os mecanismos de decisão e dar consequência a essas novas instâncias políticas.

Para que mecanismos como conselhos tenham efetividade com vistas às expectativas criadas em torno deles, são necessários no mínimo três fatores. Em primeiro lugar, estruturas estatais porosas, dotadas de aberturas que capacitem seus titulares a atuarem cooperativamente e absorverem insumos propiciados pelo contato e interlocução com os demais envolvidos. Em segundo lugar, é importante que a atuação dos profissionais do campo em questão não somente seja qualificada em suas respectivas expertises, mas que também esses mesmos profissionais nutram o apreço necessário pelo diálogo e pelos processos decisórios decorrentes da escuta recíproca. Finalmente, é crucial uma sociedade civil minimamente articulada, mobilizada e igualmente disposta ao diálogo e à escuta em seu trato com os demais atores implicados. Contempladas, ao menos parcialmente, essas três condições, teríamos, então, 
segundo os defensores desse arranjo, uma preciosa ferramenta de produção de políticas públicas eficientes e democraticamente estabelecidas.

Em resenha sobre a produção analítica brasileira dedicada ao tema, Andrade destaca alguns problemas apontados com maior frequência pela literatura especializada para o robustecimento das experiências participativas no Brasil, com destaque para os conselhos gestores e conselhos municipais (ANDRADE, 2010). Concebidos como ferramentas de participação social e controle cidadão da gestão estatal, os conselhos gestores tiveram, segundo a literatura, seu papel esvaziado em larga medida pela ação dos próprios agentes do Estado, engajados na preservação de suas margens de arbítrio e controle dos recursos públicos. Do lado da sociedade, ainda segundo Andrade, a literatura aponta três problemas adicionais enfrentados para a esperada institucionalização dos conselhos municipais (principais objetos das pesquisas empíricas realizadas): a fragilidade dos movimentos sociais, a resistência da parte deles em institucionalizar-se e firmar parceria com o Estado e, finalmente, os conflitos internos e as disputas por espaço, em muitos casos decorrentes dos vínculos dos militantes e demais atores com partidos e grupos corporativos.

Se nos diferentes campos a interação entre atores se revela complicada, no âmbito da segurança pública as dificuldades só tendem a se acentuar. Já discutimos alhures a tendência observada nas corporações policiais, sobretudo na Polícia Militar, de se perceber como vítima de estigma por parte da sociedade e de instrumentalização, por parte de lideranças políticas e autoridades (SENTO-SÉ \& SILVA; 2013). Por parte da população “civil”, as reservas quanto a aproximação a agentes da polícia, repetidamente mencionadas pelos próprios policiais, é assumida e justificada por uma longa história em que a polícia é identificada como agente de corrupção, abuso de autoridade e violência. Objeto de desconfiança por ambos os atores anteriormente mencionados, gestores e lideranças políticas não parecem ter muito fôlego, com bastante regularidade, para o penoso trabalho de diálogo, escuta e persuasão necessários para o bom funcionamento de mecanismos como os conselhos temáticos.

Teríamos, então, de certo o modo, o cenário diametralmente oposto ao desejável para a "fórmula conselhista" funcionar adequadamente. Cultura profissional pouco afeita ao diálogo combinada com um 
histórico político atravessado por ceticismo e desconfiança. A observação de campo realizada exaustivamente em diferentes conselhos comunitários de segurança do Rio de Janeiro, porém, revelou uma dinâmica um pouco diferente. Em primeiro lugar, cabe apontar o duplo papel representado por comandantes de batalhão e delegados da polícia civil nos conselhos. Obrigados por determinação legal a participarem dos conselhos das AISPs sob a jurisdição de suas respectivas unidades, os comandantes e delegados frequentemente desempenham a dupla função de profissionais do campo e representantes do poder público. Isso porque quando algum outro ator vinculado à estrutura oficial da segurança pública se faz presente é apenas por meio do Instituto de Segurança Pública. Ocorre que esse instituto, ele próprio dotado de caráter técnico e com um quadro bastante reduzido, tem dificuldades de cobrir um volume grande de encontros e atividades dos diferentes conselhos espalhados pelo estado.

Em sua dupla função, delegados e, principalmente, comandantes acabam estabelecendo relações de cumplicidade e parceria com conselheiros, muitas vezes firmando posições no e do conselho para encaminhamento de demandas por aumento de efetivo, investimento em estrutura em sua jurisdição ou coisas semelhantes. No correr dos debates, percebeu-se uma inclinação para o encaminhamento de demandas e problemas externos à alçada policial. Tal tendência, observada pelos pesquisadores de campo, foi destacada em uma série de depoimentos de membros de conselhos, quando muitos utilizaram uma aparentemente difundida comparação desses encontros com reuniões de condomínio. Essa comparação indicaria o caráter aleatório e variado dos debates travados nos conselhos e um desvio dos temas realmente relacionados com a segurança pública.

As indicações acima descritas acentuaram a relevância de um ponto por si só central em qualquer investigação sobre as dinâmicas de funcionamento de conselhos temáticos: o quê, afinal, se discute nesses encontros? A resposta a tal pergunta não somente revela muito das dinâmicas desses conselhos como, diante do quadro apresentado, sugere a exploração de outro possível ponto de análise: seria o suposto desvio dos temas realmente afetos à segurança pública um mecanismo utilizado, conscientemente ou não? Tais desvios não poderiam ser provocados pelos atores aí envolvidos com o intuito de reduzir os riscos de conflito e atenuarem eventuais efeitos de confrontos, caso questões mais sensíveis da segurança e do policiamento viessem à baila? Haveria variações de abordagens segundo 
as diferentes regiões do estado quanto ao que se discute, afinal, nas reuniões dos conselhos? Além de elucidativas e interessantes, as respostas a essas questões com base nas atas dos conselhos também têm algo de surpreendente.

A partir de uma busca pelas palavras e expressões mais recorrentes no total das atas digitalizadas no banco de dados, definimos dois grandes grupos temáticos. A um deles demos o nome de questões referentes à segurança pública. Nesse conjunto, estão reunidos todos os problemas que dizem respeito mais diretamente a questões criminais, como menções variadas a drogas, roubo, furto, etc. A um segundo grande grupo, demos o nome de questões urbanas. Ele reúne um conjunto de problemas que, embora possam se caracterizar como perturbações da ordem pública, não se caracterizariam propriamente como criminais. Mais adiante, apresentaremos a incidência de cada um desses grupos desagregados por tipo de ocorrência, o que dará ao leitor uma percepção mais precisa do que recolhemos em cada um desses universos. Por ora importa verificar a pertinência das percepções segundo as quais os problemas mais explicitamente relacionados à segurança são secundários no correr das reuniões dos conselhos. O gráfico a seguir mostra, comparativamente por região do estado, a incidência de questões alocadas em cada um dos dois grandes grupos.

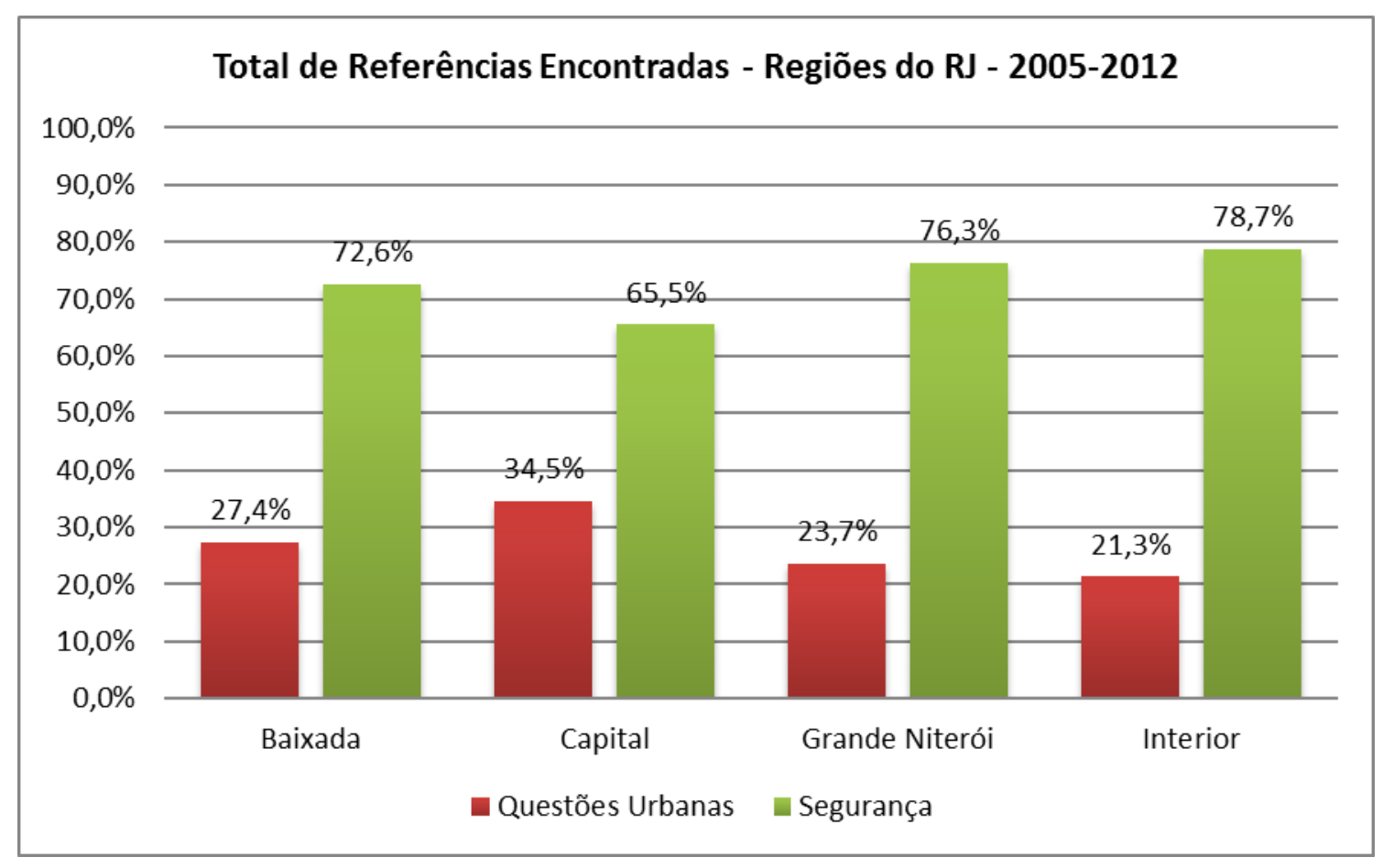

Gráfico 2. Fonte: Atas dos Conselhos Comunitários de Segurança 
Como se pode observar, em todas as quatro regiões por nós selecionadas há uma incidência significativamente maior de problemas relativos à segurança pública. Mais interessante ainda, é justamente na capital, área consagrada como a mais sensível às questões de segurança nas últimas três décadas, que a diferença entre os dois tipos por nós construídos é menor. Ou seja, é na capital que verificamos a maior incidência percentual de menções a problemas não diretamente afetos ao crime e à violência criminal. Ainda assim, contudo, também na capital a comparação dos encontros dos conselhos a reuniões de condomínio não procede. Uma segunda surpresa vem, novamente, do interior.

É justamente no conjunto de atas do interior que a incidência de menções a problemas de segurança é percentualmente maior, comparada às questões urbanas. As questões de segurança são quase 80\% dos problemas por nós apurados em registros de atas. A altíssima incidência de referências a problemas de segurança merece alguns comentários, sobretudo em função de sua discrepância em relação à percepção dos próprios participantes das reuniões.

Uma primeira hipótese para tal discrepância poderia relacionar-se a um eventual filtro aplicado por aqueles que redigem as atas. Nessa linha de interpretação, é possível pensar que mesmo involuntária e inconscientemente, ao redigir as atas os relatores se concentrem nos temas de segurança pública, deixando de lado outros assuntos que lhes pareçam dispensáveis para registro. Embora plausível, não há como testar tal hipótese. Uma segunda alternativa de interpretação seria de que a despeito a recorrência dos temas de segurança soem insuficientemente contempladas aos participantes das reuniões, ainda que prevaleçam no total dos temas debatidos. Ou seja, teríamos um típico caso de discrepância entre percepções e debates efetivamente ocorridos.

O que temos em mãos, portanto, é um forte indício de que, a despeito de possíveis desvios o foco das discussões nos conselhos de segurança é efetivamente o conjunto de problemas criminais e diretamente relacionados com a polícia. Que problemas, então, são esses? Apresentamos, na tabela a seguir, o detalhamento dos temas extraídos das atas e enfeixados em nossa grande categoria questões de segurança. 


\begin{tabular}{lrrrr}
\hline Itens & Baixada & Capital & Grande Niterói & \multicolumn{2}{c}{ Interior } \\
\hline Agressão & $2,3 \%$ & $1,3 \%$ & $1,3 \%$ & $1,9 \%$ \\
Assalto & $20,3 \%$ & $18,5 \%$ & $13,9 \%$ & $8,5 \%$ \\
Chacina & $0,8 \%$ & $0,1 \%$ & $0,3 \%$ & $0,0 \%$ \\
Cocaína & $0,2 \%$ & $0,3 \%$ & $1,8 \%$ & $1,1 \%$ \\
Crack & $2,0 \%$ & $3,6 \%$ & $3,9 \%$ & $2,0 \%$ \\
Drogas & $21,1 \%$ & $15,7 \%$ & $30,4 \%$ & $32,5 \%$ \\
Furto & $10,0 \%$ & $11,2 \%$ & $10,9 \%$ & $15,7 \%$ \\
Homicídio & $8,5 \%$ & $3,5 \%$ & $5,4 \%$ & $8,8 \%$ \\
Maconha & $0,3 \%$ & $0,6 \%$ & $1,5 \%$ & $1,6 \%$ \\
Milícia & $1,0 \%$ & $1,7 \%$ & $1,4 \%$ & $0,5 \%$ \\
Roubo & $23,1 \%$ & $31,4 \%$ & $15,4 \%$ & $15,7 \%$ \\
Saidinha & $0,8 \%$ & $1,0 \%$ & $1,8 \%$ & $0,2 \%$ \\
Sequestro & $0,3 \%$ & $2,1 \%$ & $1,4 \%$ & $1,2 \%$ \\
Tráfico & $9,1 \%$ & $8,9 \%$ & $10,7 \%$ & $10,2 \%$ \\
\hline Total & $100 \%$ & $100 \%$ & $100 \%$ & $100 \%$ \\
\hline
\end{tabular}

Tabela 2. Segurança - 2005-2012 - Regiões. Fonte: Atas dos Conselhos Comunitários de Segurança

Antes de fazer menções diretamente aos números, é importante informar ao leitor sobre determinadas escolhas de procedimento assumidas na análise. Procuramos lidar com os problemas registrados como categorias, tratando-as de modo o mais preciso possível. Daí, por exemplo, tratarmos separadamente menções a drogas, de uma forma geral, dos registros explícitos ao tráfico, ao consumo ou a tipos diferentes de drogas. Assim, apresentamos um quadro ao leitor de modo que ele próprio possa fazer inferências adicionais àquelas que nossa prudência nos permitiu fazer. 0 mesmo espírito orientado para a descrição da informação com o maior detalhamento possível nos levou a separar menções a homicídio e chacina, por exemplo.

Perceba-se que mesmo com a desagregação de drogas, tráfico, maconha, cocaína e crack, a primeira categoria, drogas, apresenta a maior incidência no interior e na Grande Niterói, representando, em ambos os casos, mais de $30 \%$ de todas as questões criminais mencionadas. A coincidência na Baixada e na capital fica por conta da predominância de menções a roubo. Nessas duas regiões, a totalização de mais da metade dos problemas registrados pela soma de roubo, assalto e furto faz parecer que prevalece a preocupação com os episódios relativos a crimes contra o patrimônio nos debates nos conselhos, comparativamente aos crimes contra a vida, a pessoa ou relativos a drogas. 
As tendências observadas merecem um comentário adicional. Tendo em vista a ênfase das autoridades policiais e de segurança em geral na "guerra contra as drogas" e pensando que tal orientação predominou principalmente na capital, surpreende um pouco verificar que é no interior e na Grande Niterói que o tema prevalece, dando lugar na capital e na Baixada à preponderância de outros tipos de preocupação. Acreditamos que essa tendência talvez vá ao encontro de uma das expectativas de desempenho dos conselhos por aqueles que são entusiastas dessa ferramenta. Segundo eles, os conselhos deveriam se ater a questões locais, territorializando os debates e orientações em detrimento da abordagem dos "grandes temas" do setor. Nessa linha, a incidência dos temas debatidos traduziria aquilo que do ponto de vista local mais inquieta moradores, comerciantes e demais atores envolvidos nas dinâmicas dos conselhos. Sendo assim, embora a questão das drogas e do tráfico, por exemplo, tenha maior visibilidade na capital, ela seria sobrepujada, em discussões mais circunscritas, a problemas relativos ao cotidiano dos participantes e às condições de fruição de seu patrimônio. No interior e na Grande Niterói, o grande incômodo adviria da questão das drogas, embora não necessariamente, ou exclusivamente, do problema de sua comercialização.

Façamos o mesmo exercício, agora, para os problemas relativos à ordem pública. Do que estão falando os frequentadores das reuniões quando lidam com esse tipo de problema? A tabela a seguir nos fornece um bom quadro a respeito.

\begin{tabular}{lrrrr}
\hline Itens & Baixada & Capital & Grande Niterói & Interior \\
\hline BarBotequimBoteco & $3,7 \%$ & $3,2 \%$ & $2,4 \%$ & $16,2 \%$ \\
BarulhoSilencio & $11,4 \%$ & $12,9 \%$ & $15,2 \%$ & $8,9 \%$ \\
CamelôAmbulantes & $1,5 \%$ & $13,3 \%$ & $9,0 \%$ & $3,7 \%$ \\
EstacionamentoFlanelinha & $6,5 \%$ & $11,7 \%$ & $8,1 \%$ & $16,1 \%$ \\
Iluminação Luz Poste & $58,6 \%$ & $31,3 \%$ & $47,9 \%$ & $44,3 \%$ \\
PodaDeArvores & $4,3 \%$ & $9,0 \%$ & $5,1 \%$ & $2,7 \%$ \\
PopulaçãoDeRua & $0,3 \%$ & $12,0 \%$ & $7,7 \%$ & $2,9 \%$ \\
Sujeira Limpeza & $13,6 \%$ & $6,5 \%$ & $4,6 \%$ & $5,2 \%$ \\
\hline Total & $100 \%$ & $100 \%$ & $100 \%$ & $100 \%$ \\
\hline
\end{tabular}

Tabela 3. Questões Urbanas - 2005-2012 - Regiões. Fonte: Atas dos Conselhos Comunitários de Segurança

Como pode ser observado, há variações perceptíveis de incidências de problemas reunidos sob a marca questões urbanas. A referência a estabelecimentos como bar, botequins e botecos reporta-se sempre a transtornos decorrentes de barulho, brigas e confusões à noite. Segunda maior incidência nas atas dos 
conselhos do interior, sua aparição é residual nas outras três regiões do estado. Se agregarmos, porém, esse item com o seguinte (Barulho/Silêncio), ao qual está vinculado substantivamente, as distâncias entre as quatro regiões ficam mais reduzidas, ainda que o interior permaneça como aquela em que o incômodo é mais acentuado.

Foco de crises urbanas e conflitos com agentes da ordem pública, os camelôs e ambulantes aparecem com alguma recorrência nas atas da capital e da Grande Niterói. Eles compõem com a chamada população de rua os personagens urbanos não criminosos mais recorrentemente tomados como objeto de discussão e de demandas por intervenções públicas, tanto na capital, quanto, em menor medida, na Grande Niterói. Nesse aspecto é interessante notar como percepções coletivas e estigmas sociais são retratados nas atas analisadas.

O ponto em comum nas quatro áreas definidas diz respeito à preponderância de discussões, queixas e demandas relativas à iluminação. Tal recorrência, que já havia sido detectada em outras etapas da pesquisa, se confirma largamente na consulta às atas. Ela já chega a quase $60 \%$ das menções na Baixada, região em que prevalecem vastas áreas que se consideram abandonadas pelo poder público; chega quase à metade das incidências de problemas mencionados na Grande Niterói e é muito alta também no interior. Mais uma vez a capital aparece como motivo de destaque. Embora também nela a iluminação seja o objeto de maior incidência, temos aí uma frequência inferior a 40\%, ou seja, o menor percentual entre as quatro regiões. Talvez essa ligeira diferença tenha a ver com uma efetividade um pouco maior da prefeitura carioca na oferta desse tipo de serviço, ainda que também nessa região as queixas sejam bastante frequentes.

A investigação sobre o conjunto de temas não alinhados diretamente às questões de segurança pública nos estimula a algumas discussões importantes sobre as dinâmicas dos conselhos comunitários de segurança pública. Como já foi mencionado, ouvimos ao longo do período em campo, bem como em entrevistas com atores engajados, repetidas queixas quanto aos desvios dos debates para temas estranhos à segurança pública e concernentes a agências não vinculadas ao sistema de justiça criminal. Nessa mesma linha de argumentação, nossos informantes justificaram os repetidos esforços de atrair atores das prefeituras para os conselhos, com o intuito de dar conta das demandas encaminhadas. Sem entrar no mérito quanto ao acerto de tais sentenças, a lista de questões destacadas das atas nos induz a qualificar tais relatos.

As demandas associadas à iluminação, assim como as menos frequentes referências à limpeza, por exemplo, ilustram uma clara percepção dos fatores de risco que tornam áreas cobertas pelos conselhos locais perigosos e com maiores incidências criminais. Sendo assim, minimiza-se o suposto alheamento dos debates mesmo quando são trazidos ao centro de discussão temas não policiais ou não criminais. 
Muitas das questões de ordem pública ou de ordenação urbana são, portanto, indiretamente ligadas à segurança. Outras, como as relativas às populações de rua ou aos camelôs também o são, ainda que em termos um pouco diferentes. Elas também incidem para a construção de cenários geradores de insegurança e de desenvolvimento de sentimentos de medo. Nesse último caso, no entanto, incidem sobre personagens em relação aos quais pesam estigmas e evitações, como ambulantes, populações de rua e jovens. Voltaremos a esse importante ponto ao fim da presente seção. Antes cabe salientar que o conjunto de temas predominantemente registrados nas atas parecem sugerir que ocorre nesses espaços um certo exercício livre compatível às teses que associam crime e insegurança a configurações espaciais.

Como já foi destacado, no correr do trabalho de campo, assim como em entrevistas com diferentes atores, como administradores vinculados à prefeitura, conselheiros ligados à sociedade e policiais civis e militares, ouvimos alusões frequentes, com indisfarçável tom reprobatório e, em alguns casos, desabonador sobre a natureza dos debates travados nas reuniões dos conselhos. O comentário recorrente compara tais encontros a reuniões de condomínio, querendo, com isso, caracterizar a miudeza e aleatoriedade dos temas. Os dados coletados nas atas corroboram a natureza dos temas apontados, mas discrepam sobre o conteúdo da avaliação de seus personagens.

Os temas tratados nos conselhos são predominantemente relativos ao arranjo urbano de circunscrição dos conselhos. Tratam de questões como ocupação do espaço, limpeza, iluminação e ordenação pública em geral. Podemos, então, ser menos críticos quanto aos rumos e conteúdos dos debates dos conselhos e os encararmos como uma espécie de experiência empírica de algumas teorias da criminologia contemporânea. Os temas são absolutamente compatíveis às teses da conhecida teoria das janelas quebradas, celebrizada e, de certa forma, vulgarizada por seu desdobramento na chamada política de tolerância zero, difundida de forma parcial e enviesada a partir do final da década de 1990.

Como é sabido, a teoria das janelas quebradas postula que um ambiente degradado estimula comportamentos predatórios e criminais (KELLING \& COLLES, 1996). Desse modo, a intervenção sobre o ambiente, sua preservação em condições limpas, iluminadas e favoráveis à ocupação pública seriam poderosos fatores de prevenção e de redução do crime. De forma semelhante, as teorias situacionais também enfocam o ambiente urbano (CLARKE, 1997; SKOGAN, 1990) como locus privilegiado de intervenção tendo em vista a redução e a prevenção do crime em determinadas áreas. Em ambos os casos, dispomos de poderosos argumentos, ainda que fundados em evidências empíricas nem sempre conclusivas, de que tratar da ordenação urbana pode representar um insumo importante para o incremento da segurança e, sobretudo, para a redução do sentimento de insegurança e vulnerabilidade local. Pode-se, com isso, postular que de forma intuitiva ou ao menos com base em uma espécie de "empiria de bairro", os conselheiros travam, a despeito da apreciação negativa de 
alguns de seus pares, discussões diretamente relacionadas à segurança, mesmo quando envolvidos nas supostas conversações próprias a reuniões de condomínio.

Um último ponto acerca das questões e abordagens dos conselhos deve ser recuperado. Como já foi mencionado no início do presente artigo, a criação dos conselhos foi animada por, entre outras razões, uma expectativa de que tal arranjo implicaria a democratização de políticas públicas em diferentes setores. Tal expectativa também veio à baila no contexto da criação dos conselhos comunitários de segurança. De certo modo, ainda que as reuniões contem com poucas presenças, que por definição os conselhos tenham poderes limitados, que haja um certo protagonismo dos atores estatais e que não haja a expectativa de discussão de grandes questões (o foco é explicitamente territorializado), é indiscutível que a abertura dessas instâncias introduz a possibilidade real de que as abordagens para a segurança no âmbito local sejam discutidas. Do mesmo modo, tais espaços funcionam, ou podem funcionar, como mecanismos de aproximação das autoridades policiais de uma parcela da população gerando, assim, alguns mecanismos de responsabilização no desempenho de suas funções. Pode-se dizer, portanto, que há certa democratização no processo de abordagem da segurança, ainda que em termos bem modestos se comparados às expectativas participativas dos anos de 1980 e 1990 . 0 mesmo não pode ser dito no que tange aos rumos dos debates e a algumas das orientações solicitadas, o que é, de certa forma, ilustrado pelas demandas em relação às populações de rua e aos ambulantes, por exemplo.

O que encontramos nas atas dos conselhos corrobora em larga escala o que já divisáramos nos conselhos em que participamos de reuniões. São comuns partirem de moradores e comerciantes locais demandas por medidas policiais duras e ações repressivas. Tivemos oportunidade de testemunhar, inclusive, queixas pelo que por vezes era encarado como complacência da polícia frente a condutas de desordem e a personagens "perigosos". Testemunhamos, durante o trabalho de campo, situações em que as autoridades policiais alegavam não ter mandato para ações repressivas a que eram instados. Em algumas dessas ocasiões, nos víamos diante do curioso quadro em que representantes das polícias, comumente identificadas com o arbítrio, o uso exagerado da força e a discricionariedade, eram mais moderados e tolerantes do que os moradores e demais participantes das reuniões. Essa observação é da maior importância para uma discussão teórica e crítica mais geral sobre em que medida participação civil representa necessariamente democratização de políticas. É razoável imaginar que a sociedade civil, ou sua parcela participativa não representa, necessariamente, valores democráticos e pautados pela tolerância.

Outro ponto a se observar diz respeito ao que não aparece no registro das atas. Como será destacado na próxima seção, dedicada aos atores participantes dos conselhos, a instituição e os profissionais mais frequentemente registrados são as polícias e os seus profissionais. Também na abertura da próxima seção explicaremos algumas das razões para a massa de referências à polícia. Por ora, cabe sublinhar 
que são encontradas no conjunto de atas 15600 citações a Polícia Militar/PM, 14407 a polícia/policial, 1438 menções a Batalhão/BPM, 7478 a Delegacia/DP, 2010 a Polícia Civil, 359 referências a UPP, enquanto que a palavra quartel aparece 274 vezes. Numa primeira olhada, tais informações evidenciam imediatamente a maior frequência de referências a policiais militares e à Polícia Militar, comparativamente à Polícia Civil. Há algumas explicações para isso, mas as deixaremos para mais adiante. O que cabe esclarecer é que, intrigados com a avassaladora ainda que compreensível recorrência a menções às instituições policiais e a seus profissionais, buscamos a frequência de citações a violência policial e a violência da polícia.

A não localização das duas combinações citadas no pacote de atas utilizadas como amostragem para a definição dos temas de análise já havia chamado nossa atenção. Lançadas já em estágio adiantado de nossa discussão empírica, encontramos um resultado surpreendente e desconcertante. A palavra policial aparece associada à violência em apenas três oportunidades. Simplesmente não há registro de combinação da palavra polícia à palavra violência. Esse é um caso típico, nos parece, em que a ausência de dados soa mais eloquente do que sua existência. Como a hipótese de inexistência de violência policial é totalmente impensável mesmo para os mais entusiastas defensores do status quo da polícia fluminense, ficamos com a difícil tarefa de buscar outra explicação. Temos duas, que não são excludentes entre si.

Não é absurdo pensar que em algumas ocasiões em que apareceu, o tema da violência policial simplesmente não tenha sido registrado em ata. Isso talvez se justifique, baseado na suposição de que o registro das atas pode operar um filtro sobre o que de fato se trata nas reuniões dos conselhos. Ocorre que ao nos vermos diante da ausência de menções e queixas dessa natureza, sobre violência ou abuso policial, pensamos em nossa própria experiência de campo. De fato, nas reuniões presenciadas as queixas contra a polícia são mais orientadas pela solicitação de maior presença, contundência e operacionalidade policial do que propriamente por eventuais desvios de conduta. Rigorosamente, não houve um único pesquisador de campo que tivesse lembrança sobre o surgimento desse tema nas reuniões. Daí a ocorrência de uma segunda explicação para isso.

Talvez a omissão a questões relativas a abusos ou desvios de conduta por parte de policiais se dê pela criação de uma certa cumplicidade e senso de cooperação desenvolvido no âmbito dos conselhos. Tal tendência levaria à rotinização do desvio de determinados temas mais espinhosos, que pudessem gerar arestas muito intensas, ou que não atingiriam o público específico que frequenta as reuniões. Teríamos, então, um caso curioso em que a aproximação polícia/comunidade almejada pelo formuladores da ideia dos conselhos comunitários de segurança seria bem sucedida ainda que não necessariamente para o aprimoramento do trabalho policial, mas pela celebração de pactos de silêncio sobre certas questões. Acreditamos que essa é uma explicação bastante plausível para a omissão de questões espinhosas como a violência policial. 
Finalmente, o que é mais difícil de aceitar, embora não deva ser descartado, o problema da violência policial pode simplesmente não seja reconhecido como uma questão a ser abordada por aqueles que se encontram hoje envolvidos nos trabalhos dos conselhos comunitários de todos os cantos do estado do Rio de Janeiro. Nesse caso, estaríamos diante do preocupante cenário em que a participação civil se revele insuficiente para tratar de uma das mais sérias questões de segurança pública relativas ao padrão de interação polícia/sociedade.

A constatação de que a omissão quanto a temas como a violência policial ou da polícia é generalizada somente nos é permitida pela análise abrangente da documentação disponível sobre os conselhos. Para a interpretação desse dado, temos que, de novo de forma tentativa, lançar mão do que foi observado in loco em alguns conselhos específicos. Inclinamo-nos a julgar que estamos diante de uma espécie de efeito perverso do espírito de colaboração e de aproximação almejados para estes espaços. Possivelmente, a criação de tais canais suscitou a definição de certos limites e barreiras que, tacitamente, ficam reconhecidos como intransponíveis. Sua ultrapassagem talvez seja encarada como algo que levaria a um tensionamento capaz de romper os canais e interromper o circuito de cooperação. Fato é que se nossa interpretação procede, um dos principais recursos dos conselhos, concorrer para uma mudança no modus operandi das polícias fluminenses, fica irremediavelmente invalidado.

A aposta na democratização de políticas pela via dos conselhos pode, portanto, ser cumprida no que diz respeito à circulação de ideias, a aproximação entre atores e a ampliação dos espaços de diálogo. Por outro lado, é certamente precipitado julgar que os conselhos impactam efetivamente a forma como a segurança pública é abordada e praticada por aqueles nela mais diretamente implicados. A criação de canais de diálogo por si só não parece equivaler a uma ampliação do espectro de iniciativas e enfrentamentos para os diferentes problemas identificados como direta ou indiretamente associados ao tema de competência do conselho. Se é assim, um ponto dos mais relevantes para se explorar o alcance dos conselhos em ampliação e diversificação de diálogo refere-se aos atores mobilizados nesses mesmos debates. A pergunta que se coloca, então, é: quem são os atores públicos ou privados que participam das reuniões dos conselhos de segurança pública ou são nelas mencionados.

\section{Os atores}

A presença constante de comandantes dos batalhões, delegados das delegacias distritais ou representantes de uns e de outros chama atenção a qualquer um que acompanhe as reuniões dos conselhos comunitários de segurança do Rio de Janeiro. Pelo menos é assim naqueles conselhos cujas reuniões foram acompanhadas durante um período de cerca de três anos de campo. Dado o volume de 
referências constantes nas atas, tudo leva a crer que essa é uma tendência bastante expressiva nos conselhos que mantêm reuniões periódicas. Isso leva a crer que o trabalho feito a partir de 2005 por parte do ISP estimulando a presença das autoridades policiais e criando constrangimentos para eventuais absenteísmos tem funcionado satisfatoriamente.

No universo policial, A Polícia Militar apresenta uma incidência significativamente maior do que a Polícia Civil. Encontramos nas atas 17312 menções à Polícia Militar, quartel ou batalhão, contra 9488 referências à Polícia Civil, policiais civis, delegacias ou DPs. Encontramos ainda 14407 menções genéricas a polícia ou policial e 359 citações a UPP. O maior volume de menções à Polícia Militar e afins é explicável pelo claro protagonismo destinado a ela quanto à criação e rotinização das reuniões dos conselhos. De qualquer modo, a presença da Polícia Civil é também digna de nota.

Para além das forças policiais, atores citados preferencialmente nas atas, cabe saber que outros aparecem com regularidade e identificar eventuais variações segundo os critérios por nós utilizados. Durante o acompanhamento de campo percebemos, por exemplo, a participação regular de atores vinculados à prefeitura do município do Rio de Janeiro. Dentre eles, chamou nossa atenção positivamente, por exemplo, a regularidade com que guardas municipais ocupam as mesas de reunião para a prestação de contas e participação nos debates travados. No sentido inverso, não é comum a presença de representantes de instituições do sistema de justiça criminal, além das polícias civil e militar. Talvez tal ausência se explique pelo caráter territorializado e circunscrito que foi se consolidando em torno dos conselhos. Ainda assim, contudo, seria de se esperar que eventualmente outros atores do sistema estivessem presentes nos encontros, mesmo que fosse para participar somente de debates pontuais. Foi na expectativa de traçar um quadro mais geral de participação de atores coletivos, públicos ou privados, que buscamos definir a recorrência com que os diferentes atores são citados em atas.

\begin{tabular}{ccccc}
\hline Ator & Baixada & Interior & Grande Niterói & Capital \\
\hline COMLURB/Lixeiro/Gari & $0,75 \%$ & $0,10 \%$ & $0,06 \%$ & $0,23 \%$ \\
Governo/Governador/PoderEstadual & $15,74 \%$ & $9,03 \%$ & $18,88 \%$ & $13,29 \%$ \\
GuardaMunicipal & $12,04 \%$ & $18,86 \%$ & $15,45 \%$ & $16,39 \%$ \\
Hospital/UPA/Posto & $8,93 \%$ & $3,48 \%$ & $3,99 \%$ & $4,83 \%$
\end{tabular}




\begin{tabular}{|c|c|c|c|c|}
\hline LIGHT/AMPLA & $3,70 \%$ & $2,22 \%$ & $2,47 \%$ & $2,62 \%$ \\
\hline Prefeitura/Prefeito/PoderMunicipal & $33,32 \%$ & $34,83 \%$ & $29,20 \%$ & $32,91 \%$ \\
\hline UPP & $1,89 \%$ & $0,84 \%$ & $1,02 \%$ & $1,12 \%$ \\
\hline Bombeiros & $3,07 \%$ & $5,18 \%$ & $3,28 \%$ & $4,18 \%$ \\
\hline ConselhoTutelar & $7,16 \%$ & $8,55 \%$ & $7,97 \%$ & $8,08 \%$ \\
\hline GuardaCivil & $0,24 \%$ & $3,36 \%$ & $0,15 \%$ & $1,77 \%$ \\
\hline Judiciário & $0,90 \%$ & $1,40 \%$ & $1,89 \%$ & $1,43 \%$ \\
\hline MP/MinistérioPublico & $1,81 \%$ & $4,36 \%$ & $4,94 \%$ & $3,96 \%$ \\
\hline $\mathrm{OAB}$ & $10,11 \%$ & $7,10 \%$ & $10,44 \%$ & $8,71 \%$ \\
\hline SEOP/ChoquedeOrdem & $0,35 \%$ & $0,68 \%$ & $0,25 \%$ & $0,49 \%$ \\
\hline Total & $100,00 \%$ & $100,00 \%$ & $100,00 \%$ & $100,00 \%$ \\
\hline
\end{tabular}

Tabela 4. Atores do Estado 2005-2012 - Regiões

Reunidas nas rubricas prefeitura, prefeito e poder municipal, temos a maior incidência de citações nas atas nas quatro regiões do estado. Reforçando a centralidade do poder local, vemos que o segundo ator mais citado na capital e no interior é a Guarda Municipal. Na Baixada e na Grande Niterói, a guarda é a terceira mais citada, apresentando em ambas percentuais bastante altos e ficando atrás apenas da rubrica governo/governador/poder estadual. Este último aparece em terceiro onde a guarda está em segundo lugar (capital e interior).

Não existem grandes variações entre as regiões destacadas em relação aos atores citados. Além da forte presença do poder municipal, cabe destacar a baixa incidência de atores como Ministério Público/MP, bombeiros, judiciário ou outros, ainda mais residuais, atores vinculados direta ou indiretamente ao sistema de justiça criminal. Também é intrigante a baixa referência a atores como LIGHT/AMPLA ou Comlurb, em função do volume de menções aos problemas relativos ao campo de atuação dessas empresas. Por outro lado, pareceu interessante a incidência acima de $10 \%$ de menções a OAB na Baixada e na Grande Niterói e o percentual próximo disso na capital e no interior. 0 percentual de citações aos conselhos tutelares nas quatro regiões também merece destaque e parece sugerir que, ainda que muitas vezes de forma torta, crianças e adolescentes são objeto de discussão nos conselhos das quatro regiões destacadas.

\section{Conclusão}


Pensados como mecanismos de incremento da participação popular nos processos decisórios e de redução do imenso abismo que existe, historicamente, entre as agências do Estado e a sociedade no Brasil, os conselhos de política têm sido objeto de um grande volume de análises críticas há pelo menos duas décadas. Monográficos em sua maioria, os trabalhos nesse campo têm convergido fortemente para a relativização do potencial dos conselhos tal como encarados nas décadas de 1980 e 1990 nos mais variados campos em que foram encampados. Nesse período, os conselhos eram tidos como um dos principais instrumentos de abertura do Estado, de erosão de suas estruturas excludentes e autoritárias e de aprendizado cívico por parte dos atores da sociedade civil.

Ao entusiasmo acrítico, as pesquisas empíricas contrapõem a dura realidade que oferece uma série de fatores que limitam e redefinem o rendimento dos conselhos: dificuldade de interação entre os diferentes atores envolvidos (representantes do Estado, profissionais e sociedade civil); interferência de interesses político-partidários e/ou corporativos na atuação desses atores; assimetria no acesso a informação e outros recursos importantes para a atuação nos conselhos; tradição autoritária do Estado e baixa cultura cívica na sociedade são os mais repetidamente apontados. É fácil notar que alguns desses aspectos frequentam a literatura sociológica e política brasileira há décadas. Ainda assim, deve-se chamar a atenção para o fato que as dificuldades não invalidam a experiência e seu potencial democrático. Assim como em outras experiências participativas, os conselhos são um instrumento de aproximação, de criação de canais para que o discurso e o debate circulem e os atores se encontrem em interações face a face.

No que diz respeito ao campo da segurança pública, a simples ideia de trazer também para ele a experiência "conselhista" pode ser considerada muito significativa. Com isso, dá-se um passo importante para reconhecer a segurança pública como um campo de políticas sociais e o bem que ela provê como um direito que deve ser franqueado isonomicamente para todos. Em sua aplicação temos hoje no Rio de Janeiro um quadro razoavelmente consagrado e, à luz dos documentos aqui analisados, difundido indiferentemente a todas as regiões do estado, embora sua intensidade varie. Para o bom funcionamento dos conselhos fica claro que o empenho do Estado é crucial, sendo mais intensas e 
recorrentes as atividades nos momentos em que os órgãos do Estado mais se empenham nesse objetivo.

Pensando estritamente nas informações extraídas das atas das reuniões, temos que a participação das polícias contrasta com a omissão de outras agências do sistema de justiça criminal. O recorte territorial dos conselhos impacta, ao que tudo indica, os termos e os temas dos debates. Há uma clara tendência à criação de interação positiva entre os atores, patenteada pela evitação a temas muito polêmicos ou passíveis de gerar conflito. Nas atas predominam menções a temas relativos à criminalidade com maior tendência a provocar impactos na sensação de segurança e na ordem urbana. Além deles, contudo, são muito frequentes as menções a problemas não criminais, mas que têm igual potencial de perturbação da ordem.

A contrapartida do ponto destacado anteriormente é uma completa omissão em relação aos grandes temas e às grandes questões da segurança pública e das políticas adotadas em larga escala para o estado. Desse modo, pode-se dizer que o impacto dos conselhos comunitários para a política de segurança do estado é bem baixo, se não completamente inexistente.

O protagonismo do Estado na animação da experiência dos conselhos comunitários de segurança pública é traduzido pela intensa participação das autoridades policiais que aparecem, assim, com uma dupla face nesses fóruns: o de agentes do Estado e dos profissionais especializados no tema relativo ao conselho. Nesse sentido, a experiência, tal como se configura presentemente, acaba reiterando uma percepção que se queria superar: a de que a segurança pública é especialmente um problema de polícia. Depois de pouco mais dez anos do último esforço concentrado por parte das autoridades estatais para a consagração dos conselhos comunitários de segurança pública, pode-se dizer que existe um longo período de acúmulo. Outros trabalhos, em escala ou mais monográficos, serão muito bem vindos para uma devida estimativa sobre os efeitos pretéritos e potencialidades futuras desse modelo, sobretudo quanto ao funcionamento da instituição que mais efetivamente participa, por parte do Estado, desse processo: a Polícia Militar do Estado do Rio de Janeiro. Estimar a medida com que essa aproximação 
interfere no trabalho de policiamento ostensivo como um todo é um desafio sociológico e político interessante e que vale a pena ser levado adiante.

\section{REFERÊNCIAS}

AVRITZER, Leonardo. Instituições participativas e desenho institucional: algumas considerações sobre a variação da participação no Brasil democrático OPINIÃO PÚBLICA, Campinas, vol. 14, nº 1, Junho, 2008, p.43-64

ANDRADE, Ilza Araújo Leão de. Participação política não eleitoral ou partidária: associação, conselhos e orçamento participativo. Em MARTINS, Carlos Benedito \& LESSA, Renato. Horizontes das ciências sociais. Ciência política. São Paulo: ANPOCS/Instituto Ciência Hoje/Discurso Editorial/Barcarolla, 2010.

CLARKE, R. V. Situational crime prevention: successful case studies. Monsey: Criminal Justice Press, 1997.

DAGNinO, Evelina. Sociedade civil e espaço público no Brasil. Em Sociedade civil e espaços públicos no Brasil. São Paulo: Espaço e Tempo, 2002.

GOHN, Maria da Glória. Conselhos gestores e participação sócio-política. São Paulo: Ed. Cortez, 2003.

KELLING, G.; COLLES, C. Fixing broken windows: restoring order and reduction crime in our community. Nova York: New York Free Press, 1996.

SENTO-SÉ, João Trajano \& SILVA, Anderson M. de Castro. A polícia e o espelho da sociedade. Interseções, v.5. n 2. P $329-355, \operatorname{dez} 2013$

SENTO-SÉ, João Trajano; FERREIRA, Thiago; SANTOS, Anastácia Cristina. Os conselhos comunitários de segurança pública do Rio de Janeiro. Institucionalização e participação. Desigualdade \& Diversidade - Revista de Ciências Sociais da PUC-Rio, nº 11, pp. 99-114, ago/dez, 2012

SKOGAN, W. G. 1990. Disorder and decline: crime and the spiral of decay in American neighborhoods. Berkeley/Los Angeles: University of California Press.

TATAGIBA, Luciana. Os conselhos gestores e a democratização das políticas públicas no Brasil. Em Sociedade civil e espaços públicos no Brasil. São Paulo: Espaço e Tempo, 2002. 